\title{
The Endothelial Metamorphoses-Spindle Cell Haemangioma
}

\author{
Anubha Bajaj* \\ Histopathologist in A B Diagnostics, New Delhi, India \\ Submission: April 27, 2020; Published: May 12, 2020 \\ *Corresponding author: Anubha Bajaj, Histopathologist in A B Diagnostics, New Delhi, India
}

\section{Introduction}

Weiss and Enzinger described a contemporaryvascular tumour formerly denominated as "spindle cell haemangioendothelioma" in 1986, a neoplasm which was considered to represent an unusual variety of low-grade angiosarcoma. However, as the terminology was suggestive of malignant potential, the neoplasm was subsequently designated as a "spindle cell haemangioma" [1]. The tumefaction demonstrates a localized reoccurrence and is devoid of potential, distant metastasis. Spindle cell haemangioma can be described as a benign, possibly reactive process appearing as a solitary or multiple, syndromic, or non syndromic disorder. Albeit, spindle cell haemangioma is a distinctive, benign, vascular neoplasm which is associated with Maffucci syndrome [1].

\section{Disease Characteristics}

Spindle cell haemangioma frequently arises within cutaneous surfaces, subcutaneous tissue, or mucous membranes. It is common within distal extremities of young adults. Neoplastic incrimination occurs within a divergent age group. Spindle cell haemangioma emerges within diverse anatomic sites such as skeletal muscle, head and neck, retroperitoneum, mediastinum, or spinal cord. Spindle cell haemangioma lacks a gender predisposition and demonstrates an equivalent incidence amidst males and females. The neoplasm can displace circumscribing anatomic structures and restrict mobility of implicated organ $[1,2]$. Of obscure pathogenesis, exact biological behaviour of spindle cell haemangioma is unknown. Nevertheless, spindle cell haemangioma can be cogitated as a benign or a reactive neoplasm or a thrombosed, pre-existent vascular lesion with subsequent recanalization $[1,2]$.

\section{Clinical Elucidation}

Overt clinical symptoms or physical anomalies can be absent. Spindle cell haemangioma can represent as a solitary, well circumscribed, gradually progressive lesion, a few centimetres in magnitude with extension into abutting soft tissue or viscera. Superimposed cutaneous surface is intact and devoid of discoloration accompanying a vascular lesion. Majority of lesions delineate reddish- purple nodules situated underneath cutaneous surfaces [2]. Spindle cell haemangioma is gradually progressive and nodules of 1 centimetre to 2-centimetre dimension are frequently enunciated [2]. Infrequent lesions delineated within deep-seated soft tissue can exhibit expansion or displacement of abutting anatomic structures. Pulmonary incrimination can emerge as multiple chest nodules [2,3]. Although preliminary lesions of spindle cell haemangioma are usually asymptomatic, subsequent presentation can engender cosmetic disfigurement which is a common indicator for cogent surgical intervention [3].

\section{Histological Elucidation}

A satisfactory tissue sampling can be obtained with specialized manoeuvres such as thoracoscopy, incisional or excisional biopsy. Several, dark- red nodules of varying magnitude are identified. The lobular neoplasm is firm in consistency. Microscopically, spindle cell haemangioma exhibits thin- walled blood vessels layered with flattened endothelial cells. Vascular spaces are enveloped by spindle-shaped or spheroid stromal cells with mediumsized nuclei intermingled with a few vacuolated cells. Mitotic figures are infrequent [4,5]. Incisional biopsy demonstrates a lesion comprised of thin- walled blood vessels with a lining of flattened endothelial cells. Intermixed within vascular spaces is a component of spindle-shaped, spheroid or epitheloid cells, vacuolated stromal cells, and a loose, fibrous tissue stroma [4]. A bland proliferation of spindle-shaped cells is exemplified betwixt diverse vascular lumina accompanied with an extravasation of erythrocytes, akin to Kaposi's sarcoma. Vacuolated stromal cells and epitheloid endothelial cells are also discerned, a feature which is absent in Kaposi's sarcoma [4,5] (Figures 1-10).

\section{Immune Histochemical Elucidation}

Cogent tumour markers such as carcino-embryonic antigen (CEA), alpha-fetoprotein(AFP), cancer antigen 19-9 (CA19-9), cytokeratin 19 fragmentation antigen (CYFRA 21-1), neuron specific enolase (NSE), squamous cell carcinoma(SCC) antigen 


\section{Cancer Therapy \& Oncology International Journal}

are immune non-reactive in spindle cell haemangioma. Vascular immune markers such as CD31, CD34 and D2-40 are immune reactive. CD34 immune reactivity can highlight distribution of distinctive vascular articulations. Endothelial cells constituting spindle cell haemangioma are immune reactive to CD31 and
Prox1 whereas a focal immune reactivity to D2-40 is delineated $[5,15]$. Smooth muscle antigen (SMA) is immune reactive whereas human herpes virus-8(HHV-8) antigen is immune non-reactive [15].

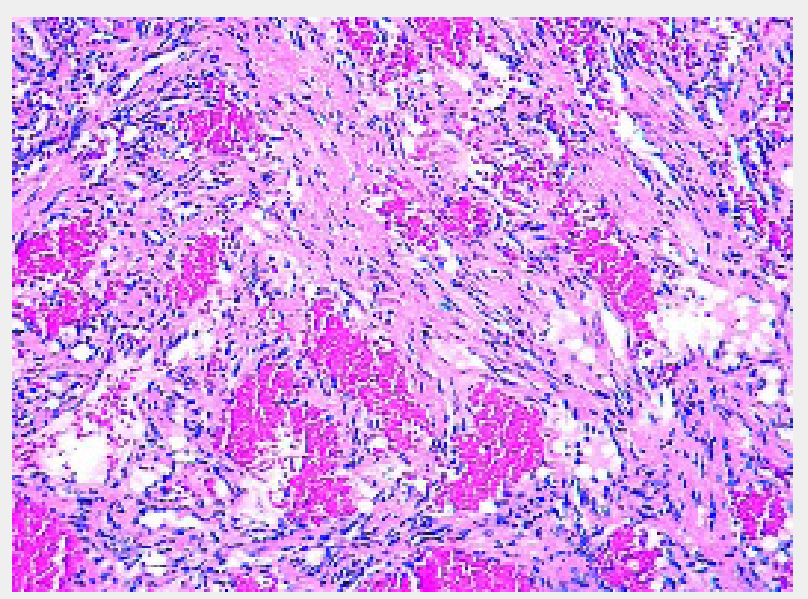

Figure 1: Spindle cell haemangioma demonstrating vascular structures lined with flattened endothelial cells, stroma with epitheloid endothelial cells and vacuolated cells with extravasation of numerous red blood cells [6].

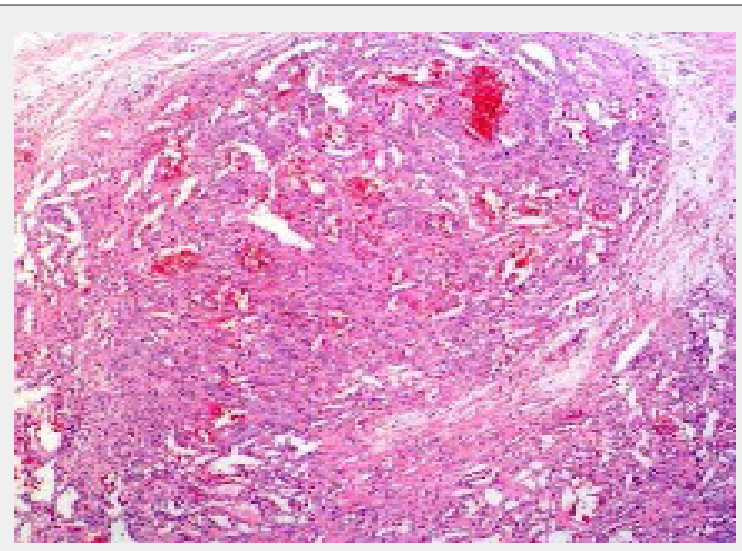

Figure 2: Spindle cell haemangioma depicting red cell extravasation, vascular structures with endothelial lining, stromal vacuolated cells and epitheloid endothelial cells [7].

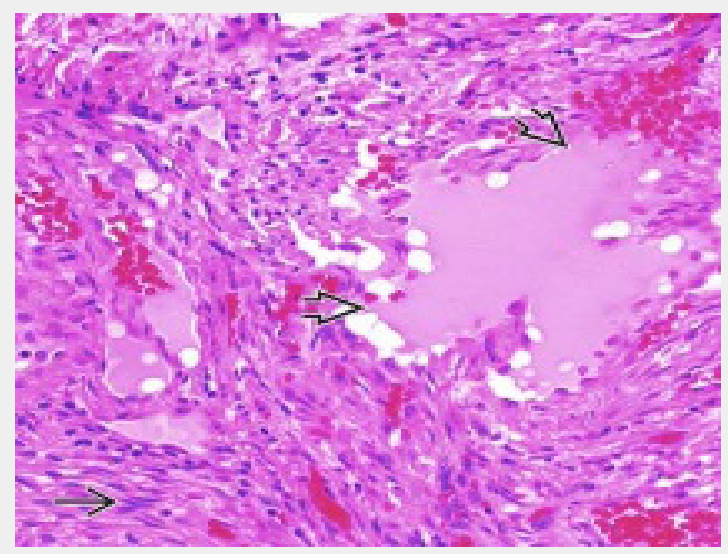

Figure 3: Spindle cell haemangioma with vascular structures layered with plump, endothelial cells, a circumscribing loose, fibrous tissue stroma with epitheloid endothelial cells and vacuolated cells [8]. 


\section{Cancer Therapy \& Oncology International Journal}

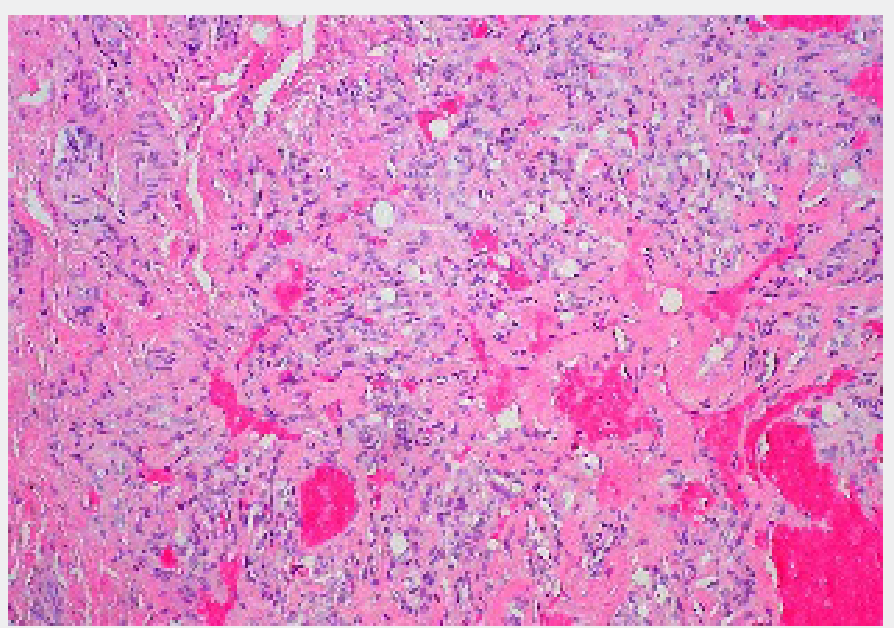

Figure 4: Spindle cell haemangioma with red cell extravasation, vascular arrangements lined with spindle to spheroid endothelial cells and an encompassing stroma with epitheloid endothelial cells [9].

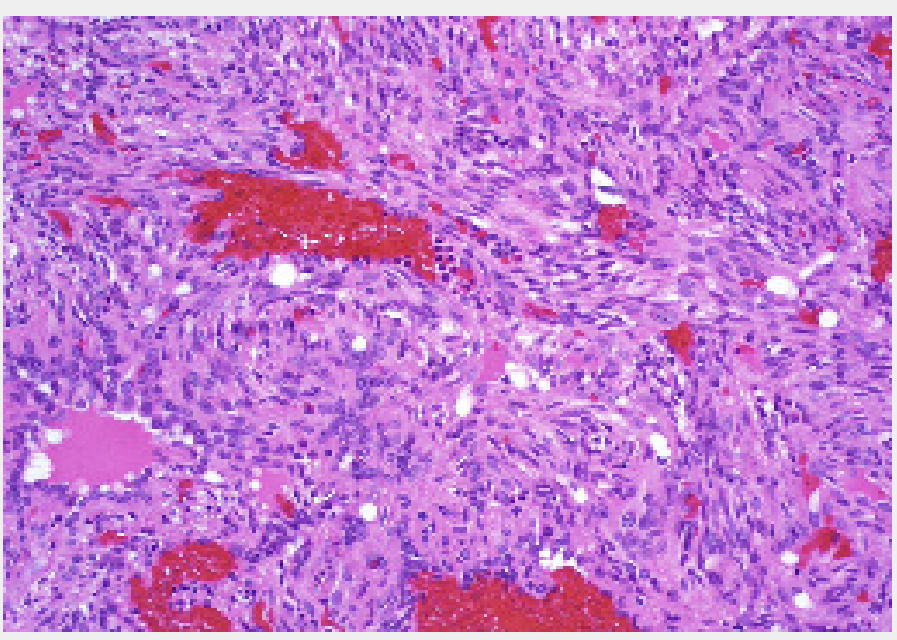

Figure 5: Spindle cell haemangioma with plump epitheloid cells and vacuolated cells confined to fibrous tissue stroma and collapsed blood vessels layered with attenuated endothelium [10].

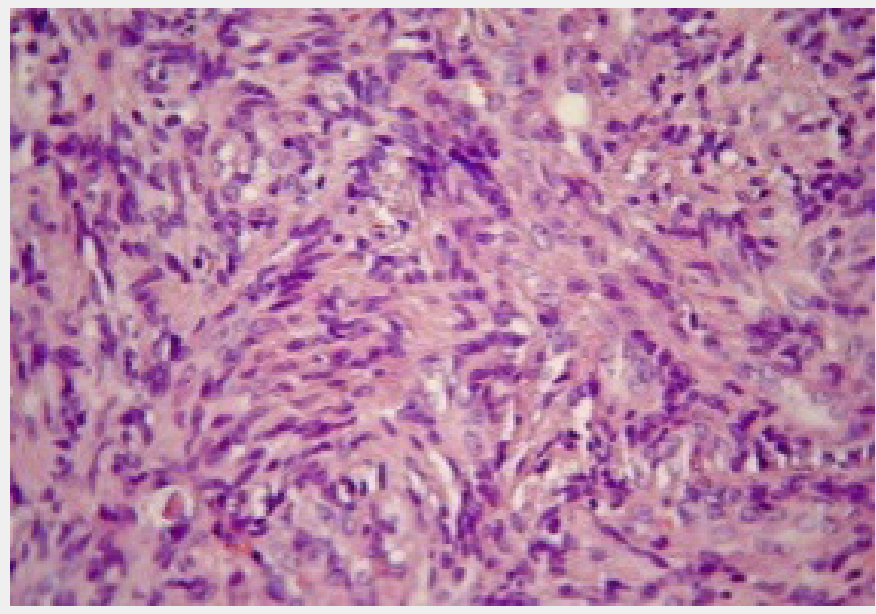

Figure 6: Spindle cell haemangioma with spheroid and epitheloid cells accumulated within loose, fibrous tissue stroma and vascular configurations lined with flattened endothelium [11]. 


\section{Cancer Therapy \& Oncology International Journal}

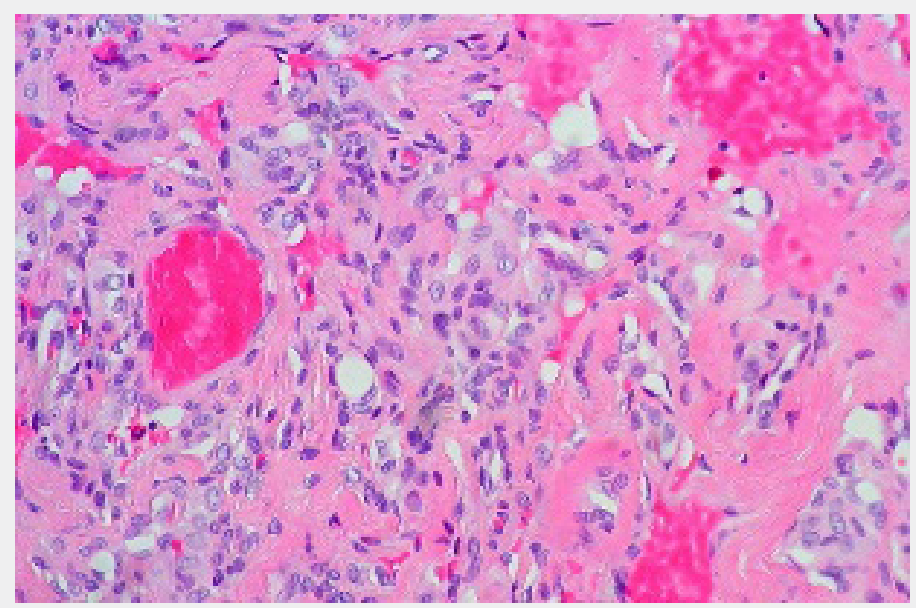

Figure 7: Spindle cell haemangioma with prominent red cell exudation, endothelium lined vascular articulations and epitheloid endothelium with vacuolated cells within the fibrous tissue stroma [12].

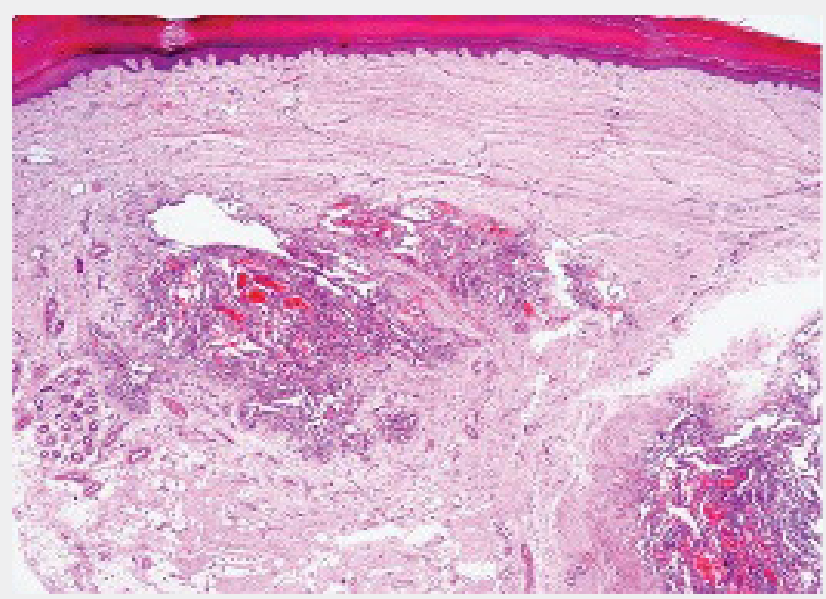

Figure 8: Spindle cell haemangioma describing a nodular articulation of vascular structures lined with attenuated endothelium, fibrotic stroma with plump epitheloid endothelium and vacuolated cells along with a superimposed stratified squamous epithelium [13].

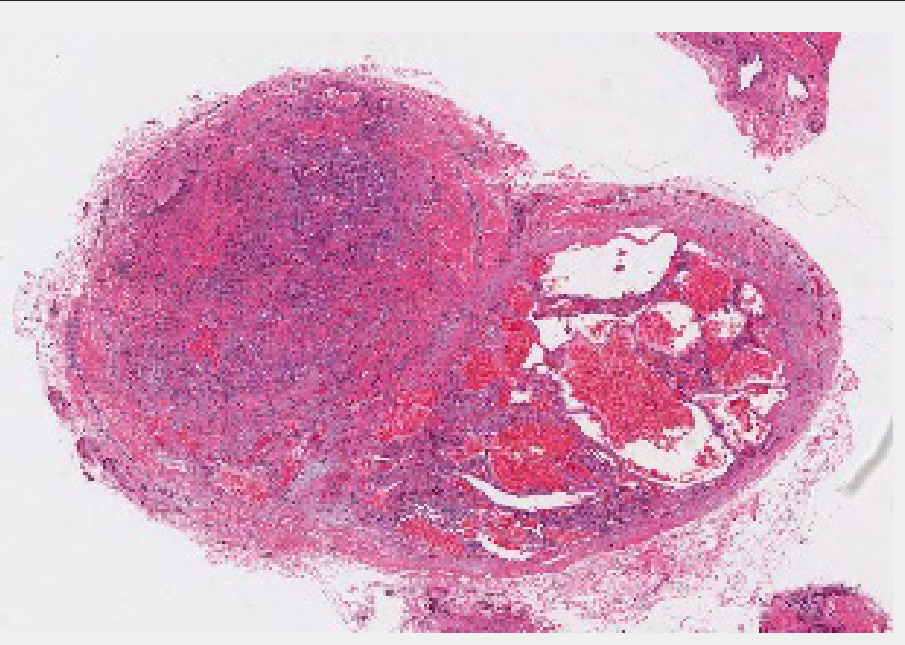

Figure 9: Spindle cell haemangioma with intense red cell extravasation with vascular nodule demonstrating endothelium lined vascular configurations and an admixture of stromal epitheloid endothelial and vacuolated cells [14]. 


\section{Cancer Therapy \& Oncology International Journal}

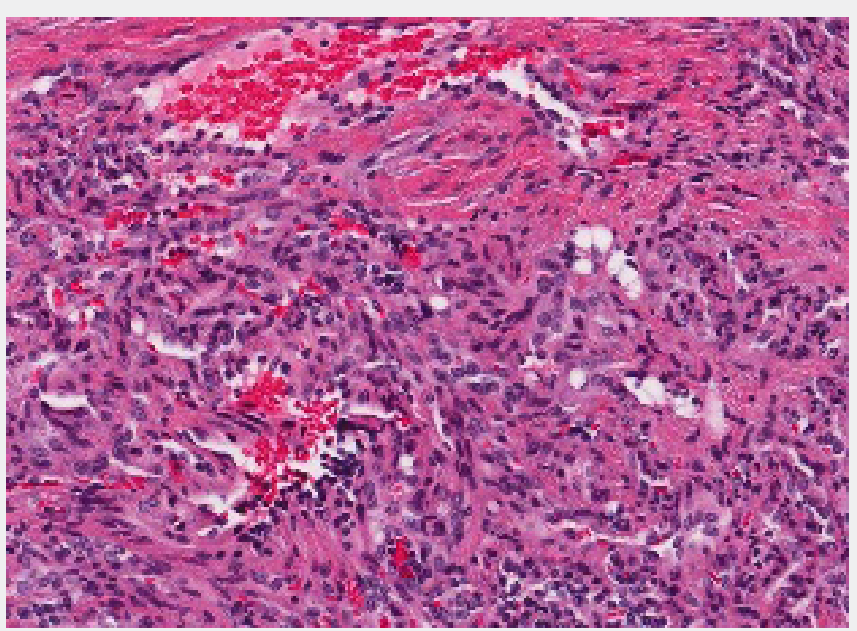

Figure 10: Spindle cell haemangioma with prominent red cell exudation admixed with vascular arrangements lined with flattened endothelium and stromal accumulation of epitheloid endothelial and vacuolated cells [14].

\section{Differential Diagnosis}

Pulmonary nodules of spindle cell haemangioma require a segregation from primary benign neoplasm such as leiomyoma or a reactive, inflammatory process of pulmonary parenchyma as with tuberculosis. Clinical and radiographic features are non- indicative of malignant transformation. Majority of lesions engendering multiple, bilateral pulmonary nodules require segregation such as pulmonary metastasis of diverse malignant neoplasia, pulmonary tuberculosis, extra-nodal lymphoma, sarcoidosis, fungal infection or infrequently discerned rheumatoid nodule and pulmonary amyloidosis [5,15]. Spindle cell haemangioma mandates a demarcation from Kaposi sarcoma, Kaposi-like haemangioendothelioma, cavernous haemangioma or epitheloid haemangioendothelioma. Histological distinction amidst spindle cell element demonstrated within spindle cell haemangioma and Kaposi sarcoma can be challenging. However, cavernous vascular spaces and epithelial vacuolated cells are usually absent in Kaposi's sarcoma. Also, Kaposi's sarcoma demonstrates a distinctive, diagnostic morphology [16].

Kaposi-like haemangioendothelioma appears within younger individuals. Malignant metamorphoses can be excluded with immune reactivity to cogent tumour markers such as carcino- embryonic antigen (CEA), alpha fetoprotein (AFP), cancer antigen 19-9 (CA19-9), neuron specific enolase (NSE), squamous cell carcinoma (SCC) antigen and cytokeratin 19 fragmentation antigen (CYFRA21-1) which are non-reactive [6,7]. Pulmonary epitheloid haemangioendothelioma (PEH) requires a segregation and is cogitated as an exceptional, vascular neoplasm commonly occurring within pulmonary and hepatic parenchyma, frequently with representation as multiple nodules within bilateral pulmonary parenchyma $[15,16]$. Pulmonary epitheloid haemangioendothelioma delineates multifocal zones with distinct reticulo-nodular configurations. Morphologically, spindle cell haemangioma is a vascular tumour constituted of a stroma composed of spindle-shaped cells and absent epitheloid cells, a cellular component which is prominent in pulmonary epitheloid haemangioendothelioma. Immune histochemical differentiation betwixt aforesaid entities could be challenging [16].

\section{Investigative Assay}

Definitive diagnosis can be obtained with a cogent tissue sampling as designated with wedge, excisional or incisional biopsy [17]. Computerized tomography of chest can demonstrate multiple, spheroidal nodules confined to bilateral pulmonary parenchyma. Nodules define a smooth perimeter and uniform imaging density wherein mammoth nodules can be situated adjacent to lung apices or upper lobes. Computerized tomography (CT) of the thoracic cavity exhibits multiple, well demarcated, occasionally calcified, homogenous nodules. Aforesaid pulmonary nodules necessitate a distinction from several benign or malignant pulmonary neoplasia $[17,18]$. Computerized tomography (CT) demonstrates a mammoth, multi-lobulated, heterogeneous, enhancing mass of intermediate density. Thus delineated, the neoplasm can reconstruct, protrude, displace, and abrogate encompassing soft tissues and viscera with minimal compression. Computerized tomography (CT) and magnetic resonance imaging (MRI) are beneficial in localizing the extent of neoplasm and direct surgical and therapeutic feasibility $[17,18]$. On radiographic evaluation, pulmonary spindle cell haemangioma demonstrates a homogenously dense nodule with a smooth border and lack of infiltration into circumscribing pulmonary parenchyma [18].

\section{Therapeutic Options}

Cogent monitoring following adequate surgical excision demonstrates asymptomatic individuals and a lack of tumour progression as assessed through computerized tomography (CT) of the chest or incriminated organs. Pre-operative diagnosis of 


\section{Cancer Therapy \& Oncology International Journal}

spindle cell haemangioma can be challenging and an adequate postoperative histological analysis with pertinent immune histochemical reactivity is mandated $[17,18]$. Various therapeutic options applicable in treating spindle cell haemangioma are surgical intervention, systemic steroids, cryotherapy, laser therapy, radiation therapy, cytotoxic drugs, selective embolization, and utilization of recombinant interleukin -2 [18]. As spindle cell haemangioma is a benign neoplasm, simple observation or an adequate surgical resection are contemplated as competent therapeutic options. The tumour is devoid of reoccurrence upon extended monitoring [18].

An acceptable, current treatment option of the benign spindle cell haemangioma is a conservative surgical excision devoid of adjuvant chemotherapy or radiotherapy. Following competent surgical extermination of the lesion, a localized reoccurrence of up to $58 \%$ is exemplified. Tumour reoccurrence is frequent in subjects depicting multiple lesions upon initial disease representation or nodules occurring adjacent to a surgical site. Majority of instances of tumour relapse manifest as multifocal tumours arising within a singular anatomic region, on account of a possible, concomitant vascular anomaly or intravascular propagation of the lesion $[17,18]$. Radiation therapy is not recommended for treating spindle cell haemangioma due to a contingent malignant metamorphosis or a radiation- induced sarcomatous transformation. Preferential treatment is a conservative surgical eradication of the neoplasm

\section{References}

1. Gbolahan 00, Fasina 0, Akinyele Olumuyiwa Adisa, Olubayo A Fasola et al. (2015) Spindle cell haemangioma: unusual presentation of an uncommon tumour. J Oral and Maxillofac Pathol 19(3): 406.
2. Duqing $X$, Zhaohong Wu, Gefei $W$ (2019) Multiple spindle cell haemangioma in both lungs: a rare case report and review of literature. J Cardiothoracic Surg 14(1): 88

3. Weiss SW, Enzinger FM (1986) Spindle cell haemangioendothelioma a low grade angiosarcoma resembling a cavernous haemangioma and Kaposi's sarcoma. Am J Surg Pathol 10(8): 521-530.

4. Hakozaki M, Watanabe TT, Tajino T, Yamada H, Kikuchi S, et al. (2012) Intraosseous spindle cell haemangioma of the calcaneus: a case report and review of literature. Ann Diagn Pathol 16(5): 369-373.

5. Marusic Z, Billings SD (2017) Histopathology of spindle cell vascular tumours. Surg Pathol Clin 10(2): 345-366.

6. Image 1 Courtesy: Pathology outlines.

7. Image 2 Courtesy: Histopathology.india.net

8. Image 3 Courtesy: Basic Medical Key

9. Image 4 Courtesy: Wikimedia commons

10. Image 5 Courtesy: Semantic Scholar

11. Image 6 Courtesy: Science direct.

12. Image 7 Courtesy: Webpathology.com

13. Image 8 Courtesy: Plastic Surgery Key.

14. Image 9 and 10 Courtesy: Dermpedia.com

15. Wang L, Gao T, Wang G, et al. (2014) Expression of Proxl, D2-40 and WT1 in spindle cell haemangioma. J Cutan Pathol 41(5): 447-440.

16. Woo JH, Kim TJ, Lee KS, Kim TS, Kim BT, et al. (2016) Epitheloid haemangioendothelioma in the thorax; clinicopathologic, CT, PET and prognostic features. Medicine (Baltimore) 95(30): e4348.

17. Sardaro A, Bardoscia L, Petruzzelli MF, Portaluri M (2014) Epitheloid haemangioendothelioma: an overview and update on a rare, vascular tumour. Oncol Review 8(2): 259.

18. Perkins P, Weiss SW (1996) Spindle cell haemangioendothelioma: an

\section{Your next submission with Juniper Publishers will reach you the below assets}

- Quality Editorial service

- Swift Peer Review

- Reprints availability

- E-prints Service

- Manuscript Podcast for convenient understanding

- Global attainment for your research

- Manuscript accessibility in different formats

( Pdf, E-pub, Full Text, Audio)

- Unceasing customer service

Track the below URL for one-step submission https://juniperpublishers.com/online-submission.php 